\title{
The Prevalence of Carotid Artery Calcification on the Panoramic Radiographs in Cappadocia Region Population
}

Yildiray Sismana, DDS, PhD,

Elif Tarim Ertas ${ }^{b}$, DDS,

Cumali Gokcec, MD,

Ahmed Menkud, MD,

Mustafa Ulkere, DDS, PhD,

Faruk Akgunluf, DDS, PhD

\section{ABSTRACT}

Objectives: The aim of this study is to determine retrospectively the presence of carotid artery calcifications (CACs) detected on panoramic radiographs (PRs) in a group of Turkish population. Further, the relationships between CACs and gender, life style, and medical history were evaluated.

Methods: During the years 2004 to 2006, a random sample of 1282 PRs was collected from patients older than 40 years who were being treated by the School of Dentistry, Erciyes University. Of these 1282 PRs, 750 PRs were included in this study. Medical data was collected from the archival records of the dental school.

Results: About 38 (5.06\%) CACs were found on the PRs of 12 (4.5\%) males and 26 (5.4\%) females. The CAC prevalence was not significantly different between the males and females ( $P=0.583)$. These calcifications were unilateral in $26(68.4 \%)$ and bilateral in $12(31.6 \%)$ subjects. Of those in the positive group, there were 12 subjects (31.58\%) with hyperlipidemia, 12 subjects $(31.58 \%)$ with hypertension, 7 subjects $(18.4 \%)$ with diabetes mellitus, 6 subjects $(15.8 \%)$ with cardiovascular disease, and 6 subjects (15.8\%) with smoking history.

Conclusions: This study has the highest CACs prevalence in comparison to the other studies. Therefore, dentists caring for subjects with dental problems should carefully evaluate their PRs for the evidence of CACs, and refer them for medical evaluation as indicated. So, incidental findings could provide life-saving information. (Eur J Dent 2007;1:132-138)

Key words: Panoramic radiograph; Carotid artery calcification; Atherosclerosis, Risk factors

a assistant Professor and Chair, Department of Oral Diagnosis and Radiology, Faculty of Dentistry, Erciyes University, Kayseri, Turkey.

${ }^{\mathrm{b}}$ Research Assistant, Department of Oral Diagnosis and

Radiology, Faculty of Dentistry, Erciyes University, Kayseri, Turkey.

Dr., Department of Endocrinology and Metabolism, Kayseri Training and Research Hospital, Kayseri, Turkey.

d Associate Professor, Department of Neurosurgery, Faculty of Medicine, Erciyes University, Kayseri, Turkey.

e Assistant Professor, Department of Conservative Dentistry, Faculty of Dentistry, Erciyes University, Kayseri, Turkey.
† Professor and Chair, Department of Oral Diagnosis and Radiology, Faculty of Dentistry, Selcuk University, Konya, Turkey.

- Corresponding author: Dr. Yildiray Sisman, DDS, PhD, Assistant Professor and Chair,

Department of Oral Diagnosis and Radiology, Faculty of Dentistry, Erciyes University, 38039, Kayseri, Turkey.

Tel: +90-352- $4374901 / 29226$

Fax: +90-352-438 0657

E-mail: drsismandyahoo.com 


\section{INTRODUCTION}

Atherosclerosis, a progressive inflammatory disorder, may lead to peripheral artery disease, coronary artery disease or stroke. The prevalence of atherosclerosis associated with mortality, and morbidity is very high in developed countries. ${ }^{1,2}$ In western societies, it is the underlying reason of about approximately $50 \%$ of all deaths. Specifically, cerebrovascular accident or stroke is the third etiology of death in USA today, preceded only by cardiovascular disease and cancer. ${ }^{1,3,4}$ Over 750,000 new or recurrent strokes occur in the United States annually. In this country, the atherosclerosis is believed to account for about approximately $50 \%$ of all embolic strokes and causes to billions of dollars in direct and indirect costs annually. ${ }^{5-7}$ Not only in the USA, but also in other countries, atherosclerosis and its more dramatic consequences-strokes and heart attacks-represent an important health problem. Although the rate of stroke death has decreased over the past decades in Spain, it is still the second reason of death in men and the first in women. ${ }^{8}$ In Turkey, stroke or cerebrovascular accident is the third etiology of death, preceded only by cardiovascular disease and cancer. ${ }^{9}$

The majority (approximately $80 \%$ ) $^{10}$ of these strokes are ischemic and due to atherosclerotic disease in the region of the carotid bifurcation. ${ }^{11}$ It was showed that Caucasian men are at greater risk for the stroke from atherosclerotic plaques that arise from carotid arteries. ${ }^{12}$ The presence of carotid artery calcifications (CACs) on standard panoramic radiographs (PRs) was first showed by Friedlander and Lande. ${ }^{13}$ They suggested that these radiographs were able to play an important role in the early diagnosis of CACs, which could result in more serious heart disease and cerebrovascular accident. ${ }^{14}$ Therefore, PRs may help us as a diagnostic tool for detecting CACs and the early diagnosis could potentially decrease the morbidity and mortality for subjects with CACs.

Recently, a number of studies have revealed the detection of CACs on PRs in many populations, ${ }^{12-23}$ but, there is no enough study regarding this topic in Turkish population. There is only one report about CACs detected by PRs in normal population in Turkey. ${ }^{24}$ The aim of the present study is to determine retrospectively the presence of CACs detected on
PRs in a group of Turkish population living in Cappadocia region. Further, the relationship between CACs and gender, life style, and medical history was evaluated. According to our knowledge, this is the first study done in Cappadocia region and investigating the risk factors related to CAC in the Turkish population.

\section{MATERIALS AND METHODS}

The study is based on 1282 PRs retrieved from the archival records. All the PRs were taken between 2004 to 2006 at the Erciyes University Faculty of Dentistry, Department of Oral Diagnosis and Radiology. The patients with or without dental problems were older than 40 years and treated with this clinic. These PRs were taken as screening films before treatment. Seven hundred and fifty $(n=750)$ of these radiographs were of good image quality. PRs that were excluded because of the subject's movements during the exposure or did not include C3 and C4 were eliminated ( $=532$ ).

All the PRs were obtained with an Orthopantomography® OP100 (Instrumentarium Corp. Imaging Division, Tuusula, Finland). The PRs were processed according to the manufacturer's recommendations in an automatic film processor. All the PRs were evaluated by the same author (YS). Each radiograph was viewed in subdued ambient light using transmitted light from a standard view box. A radiopaque nodular mass or masses adjacent to the cervical vertebrae at or below the intervertebral space between $\mathrm{C} 3$ and $\mathrm{C} 4$ were diagnosed as $\mathrm{CACs}^{23}$ (Figure 1). Patients with either unilateral or bilateral CACs on these radiographs were detected. For the differential diagnosis of CACs, other cervical calcifications such as calcified triticeous cartilage, calcified thyroid cartilage,

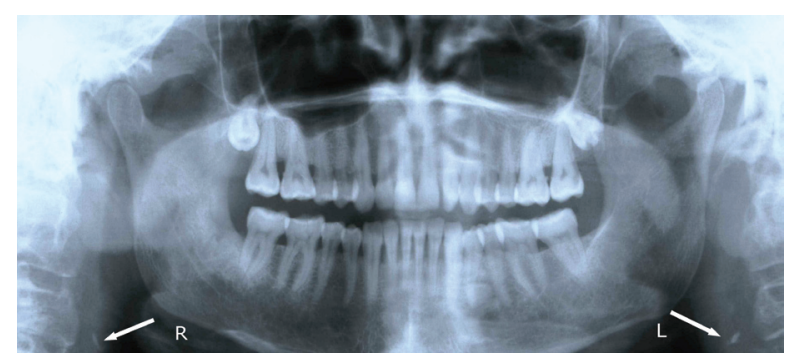

Figure 1. Carotid artery calcifications visible on the right and left neck, adjacent to the upper intervertebral space between C3 and C4 (white arrows) as shown on a panoramic radiography. 
hyoid bone and submandibular salivary gland sialoliths were excluded according to Carter's study. ${ }^{25}$ To check the intra-observer variations, all the PRs were reevaluated by the same author after one month.

Medical records of the patients with CACs were analyzed. When the CACs were detected, the medical records were reviewed for the factors related to atherosclerosis including hyperlipidemia, hypertension, renal diseases, diabetes mellitus, cardiovascular disease, smoking etc. Any relationship between CACs and gender, age, and past medical history was evaluated.

The results were analyzed with SPSS 10.0 (Statistical Package for Social Science Inc., Chicago, Illinois, USA). Data were obtained using chi-square test for comparing the CAC prevalence between the males and the females. The results were considered to have a significant difference if the significance level was lesser than .05.

\section{RESULTS}

The study population consisted of 268 males and 482 females with a mean age of $51.0 \pm 8.3$ (range: 40-83 years) at the time of PRs taken. Of the 750 individuals, $38(5.06 \%)$ were detected to have CAC on PRs. The thirty eight individuals who had CACs consisted of 12 males $(4.5 \%)$ and 26 females $(5.4 \%)$. CACs was not significantly different between the males and females ( $P=0.583$ ). The mean age of these patients at that time was $55.7 \pm 8.02$ years (men: $58 \pm 7.3$, women: $54.6 \pm 8.2$ years).

Carotid artery calcifications were seemed as a radiopaque mass or masses adjacent to or just upper the intervertebral space between $\mathrm{C} 3$ and $\mathrm{C} 4$ (Figure 1). These calcifications were unilateral in $26(68.4 \%)$ and bilateral in $12(31.6 \%)$ subjects. Of the 38 patients there were 12 bilateral (six males, six females: Table 1) CACs. Therefore, 50 CACs were detected in the 38 patients. Of the 38 ln=50 CACs) patients, $31(62 \%)$ of the CACs were located on the right side and 19 (38\%) were located on the left side.

The medical records of 38 patients with CAC were analyzed for the risk factors associated with CAC. Table 1 shows the relationship between medical history and CACs. In 38 patients with CACs, 12 subjects (31.58\%) reported hyperlipidemia, 12 subjects (31.58\%) reported hypertension, 10 subjects
(26.3\%) reported renal disease, 7 subjects (18.4\%) reported diabetes mellitus, 6 subjects (15.8\%) reported cardiovascular disease, and 6 subjects (15.8\%) reported smoking, as shown in Table 1.

\section{DISCUSSION}

Carotid artery calcification, especially close to carotid bifurcation, can result in important vascular obstruction causing stroke. ${ }^{16}$ Several factors for the stroke are stratified into no modifiable and modifiable risk factors. The former are gender, age, ethnicity, and heredity, and the latter are hypertension, diabetes mellitus, hyperlipidemia, obesity, smoking, and carotid atherosclerotic disease. ${ }^{26}$ Early detection of these risk factors reduces the morbidity and mortality. ${ }^{16}$ In 1981, it was suggested that standard PR is a useful tool in detecting patients at risk of stroke, because the CAC may be seen in the standard PR adjacent to the cervical vertebrae at the level of the C3-C4 intervertebral junction. ${ }^{13}$ Such calcification may seem as either a radiopaque vertical line or nodular radiopaque mass inferior to the angle of mandible. ${ }^{13}$ Dentists should be able to diagnose CACs and be able to distinguish them from a myriad of anatomical and pathological lesions which may be seen in the region. ${ }^{18,27,28}$ Verification of CAC must be conducted with cervical spine radiographs, angiography or Doppler ultrasound analysis and imaging. ${ }^{29}$

PRs are used routinely in the evaluation of patients with dental problems. It is not as useful as Doppler ultrasonography and three dimensional computed tomography for detecting atherosclerotic plaque in the carotid arteries and especially the stenosis of the vessels, ${ }^{30}$ but it is very cheap and non-invasive method in comparison to other imaging methods. PRs may help us in the early diagnosis and in the evaluation of CACs in patients with or without associated risk factors and decrease the morbidity and mortality due to diseases caused by atherosclerosis. ${ }^{24}$

There are only two Turkish reports investigating the CAC prevalence on PRs in normal population and in patients with end-stage renal disease (ESRD). ${ }^{24,31}$ Bayram et al ${ }^{24}$ evaluated the PRs of 4106 subjects in terms of CAC in the capital of Turkey. Of these patients, 88 patients $(2.1 \%)$ had CACs. In the current study, our CAC prevalence was higher than this study. This difference may be due to regional, dietary, and lifestyle differences 
of the subjects. We also investigated the risk fac- (risk factors and CAC on PRs) may be important for tors for CACs in all the patients. But, Bayram et the initial diagnosis and further evaluation of this $\mathrm{al}^{24}$ only evaluated the risk factors in patients with disorder. In another study, the CAC prevalence on CACs. We think that the availability of both of them PRs was investigated for the 69 adult patients with

Table 1. The demographic and medical records of the patients with carotid arterycalcifications seen on the panoramic radiographs

\begin{tabular}{|c|c|c|c|c|c|c|c|c|c|c|}
\hline Case & Gender & Age & Side & $\mathrm{HL}$ & HT & $\mathrm{RD}$ & DM & CVD & $\mathrm{S}$ & Others \\
\hline 1 & $\mathrm{~F}$ & 40 & $\mathrm{R}$ & _- & HT & $\mathrm{RD}$ & - & CVD & _ & Gout \\
\hline 2 & $\mathrm{~F}$ & 42 & $\mathrm{R}$ & _- & HT & $\mathrm{RD}$ & - & _- & _ & _- \\
\hline 3 & $\mathrm{~F}$ & 44 & $\mathrm{R}$ & _ & _- & $\mathrm{RD}$ & - & _- & & Anxiety \\
\hline 4 & $F$ & 45 & $\mathrm{R}$ & $\mathrm{n} / \mathrm{a}$ & $\mathrm{n} / \mathrm{a}$ & $\mathrm{n} / \mathrm{a}$ & $\mathrm{n} / \mathrm{a}$ & $\mathrm{n} / \mathrm{a}$ & $\mathrm{n} / \mathrm{a}$ & $\mathrm{n} / \mathrm{a}$ \\
\hline 5 & $F$ & 46 & L & - & - & - & - & - & - & Anxiety \\
\hline 6 & $\mathrm{~F}$ & 47 & $\mathrm{R}$ & $H L$ & - & & - & - & $\mathrm{S}$ & - \\
\hline 7 & $\mathrm{~F}$ & 48 & $\mathrm{R}$ & $\mathrm{HL}$ & - & $\mathrm{RD}$ & - & - & _- & - \\
\hline 8 & $M$ & 50 & $\mathrm{R}$ & - & - & - & DM & - & - & - \\
\hline 9 & $\mathrm{~F}$ & 51 & $\mathrm{R}$ & - & - & _ & - & - & _ & - \\
\hline 10 & $\mathrm{~F}$ & 51 & $\mathrm{R}$ & $\mathrm{n} / \mathrm{a}$ & $\mathrm{n} / \mathrm{a}$ & $\mathrm{n} / \mathrm{a}$ & $\mathrm{n} / \mathrm{a}$ & $\mathrm{n} / \mathrm{a}$ & $\mathrm{n} / \mathrm{a}$ & $\mathrm{n} / \mathrm{a}$ \\
\hline 11 & $\mathrm{~F}$ & 52 & $\mathrm{R}$ & $\mathrm{n} / \mathrm{a}$ & $\mathrm{n} / \mathrm{a}$ & $\mathrm{n} / \mathrm{a}$ & $\mathrm{n} / \mathrm{a}$ & $\mathrm{n} / \mathrm{a}$ & $\mathrm{n} / \mathrm{a}$ & $\mathrm{n} / \mathrm{a}$ \\
\hline 12 & $\mathrm{~F}$ & 53 & $\mathrm{R} / \mathrm{L}$ & $\mathrm{HL}$ & HT & & DM & CVD & - & - \\
\hline 13 & F & 53 & L & - & HT & $\mathrm{RD}$ & - & - & - & - \\
\hline 14 & $\mathrm{~F}$ & 53 & $\mathrm{R}$ & $\mathrm{HL}$ & _- & - & - & - & $\mathrm{S}$ & - \\
\hline 15 & M & 54 & $\mathrm{~L}$ & $\mathrm{n} / \mathrm{a}$ & $\mathrm{n} / \mathrm{a}$ & $\mathrm{n} / \mathrm{a}$ & $\mathrm{n} / \mathrm{a}$ & $\mathrm{n} / \mathrm{a}$ & $\mathrm{n} / \mathrm{a}$ & $\mathrm{n} / \mathrm{a}$ \\
\hline 16 & $M$ & 54 & $R / L$ & - & - & - & DM & - & - & - \\
\hline 17 & $\mathrm{~F}$ & 54 & $\mathrm{R}$ & - & - & - & - & - & - & - \\
\hline 18 & $F$ & 55 & L & $\mathrm{n} / \mathrm{a}$ & $\mathrm{n} / \mathrm{a}$ & $\mathrm{n} / \mathrm{a}$ & $\mathrm{n} / \mathrm{a}$ & $\mathrm{n} / \mathrm{a}$ & $\mathrm{n} / \mathrm{a}$ & $\mathrm{n} / \mathrm{a}$ \\
\hline 19 & $M$ & 55 & $\mathrm{R}$ & - & - & - & - & - & - & - \\
\hline 20 & M & 55 & L & $\mathrm{HL}$ & - & _ & - & - & $\mathrm{S}$ & _- \\
\hline 21 & $M$ & 55 & $R / L$ & - & - & $\mathrm{RD}$ & - & - & - & - \\
\hline 22 & $\mathrm{~F}$ & 56 & $\mathrm{R}$ & - & - & - & - & - & - & Anxiety \\
\hline 23 & $M$ & 57 & $\mathrm{R}$ & - & - & - & - & - & - & - \\
\hline 24 & $M$ & 58 & $R / L$ & $H L$ & HT & - & - & CVD & $\mathrm{S}$ & - \\
\hline 25 & $M$ & 58 & $\mathrm{R} / \mathrm{L}$ & - & HT & - & - & - & - & - \\
\hline 26 & $\mathrm{~F}$ & 58 & $\mathrm{R}$ & $\mathrm{HL}$ & - & - & - & - & - & Asthma \\
\hline 27 & $\mathrm{~F}$ & 58 & $R / L$ & $H L$ & HT & - & DM & - & $\mathrm{S}$ & - \\
\hline 28 & $M$ & 60 & $L$ & - & - & $\mathrm{RD}$ & $\mathrm{DM}$ & - & - & - \\
\hline 29 & $\mathrm{~F}$ & 60 & $\mathrm{R}$ & - & HT & $\mathrm{RD}$ & - & - & - & - \\
\hline 30 & F & 60 & $\mathrm{R}$ & $H L$ & HT & - & - & - & - & - \\
\hline 31 & $\mathrm{~F}$ & 60 & $\mathrm{R} / \mathrm{L}$ & $H L$ & - & - & - & - & - & - \\
\hline 32 & $M$ & 62 & $\mathrm{R} / \mathrm{L}$ & $H L$ & - & $\mathrm{RD}$ & - & CVD & $\mathrm{S}$ & - \\
\hline 33 & $\mathrm{~F}$ & 64 & $\mathrm{R}$ & - & HT & - & - & - & - & - \\
\hline 34 & $\mathrm{~F}$ & 64 & $\mathrm{~L}$ & - & - & _ & - & - & - & - \\
\hline 35 & $\mathrm{~F}$ & 65 & $\mathrm{R} / \mathrm{L}$ & $\mathrm{n} / \mathrm{a}$ & $\mathrm{n} / \mathrm{a}$ & $\mathrm{n} / \mathrm{a}$ & $\mathrm{n} / \mathrm{a}$ & $\mathrm{n} / \mathrm{a}$ & $\mathrm{n} / \mathrm{a}$ & $\mathrm{n} / \mathrm{a}$ \\
\hline 36 & $\mathrm{~F}$ & 69 & $\mathrm{R} / \mathrm{L}$ & - & HT & - & DM & CVD & - & $\begin{array}{l}\text { Tuber- } \\
\text { culosis }\end{array}$ \\
\hline 37 & $\mathrm{~F}$ & 72 & $R / L$ & $\mathrm{HL}$ & HT & $\mathrm{RD}$ & $\mathrm{DM}$ & CVD & _- & - \\
\hline 38 & M & 79 & $R / L$ & $\mathrm{n} / \mathrm{a}$ & $\mathrm{n} / \mathrm{a}$ & $\mathrm{n} / \mathrm{a}$ & $\mathrm{n} / \mathrm{a}$ & $\mathrm{n} / \mathrm{a}$ & $\mathrm{n} / \mathrm{a}$ & $\mathrm{n} / \mathrm{a}$ \\
\hline Total & & Mean $=55.7$ & & 12 & 12 & 10 & 7 & 6 & 6 & \\
\hline
\end{tabular}

HL, Hyperlipidemia; HT, Hypertension; RD, Renal diseases; DM, Diabetes mellitus ; CVD, Cardiovascular disease; S, Smoking; na, not available 
renal disease (35 with renal transplant recipients and 34 with ESRD). ${ }^{31}$ It was reported that the CAC prevalence was $15.7 \%$ in patients with renal transplant patients and $17.6 \%$ in patients with haemodialysis. ${ }^{31}$ This high prevalence was due to ESRD leading to atherosclerosis.

Recently, the literature has been reported several articles on incidental CACs in the carotid bifurcation region detected by PRs in the other populations. ${ }^{12-23}$ Pornprasertsuk-Damrongsri and Thanakun, ${ }^{16}$ found a rate of $2.5 \%$ in dental school patients showing CAC on the PRs. In the present study, the prevalence of positive findings of CAC on routine dental PRs (5.06\%) was higher than the report in Thai population (2.5\%). Carter et $\mathrm{al}^{32}$ evaluated the CAC prevalence on PRs in 1175 newly accepted dental school patients in State University, New York. It was showed that the prevalence was $3.6 \%$ in this population. In other study, Tamura et $\mathrm{al}^{15}$ retrospectively investigated the prevalence on 2568 PRs in a Japanese population. The CAC prevalence in this sample was $4.13 \%$. These differences in terms of the CAC prevalence in all the populations might be due to ethnicity, dietary factors, lifestyle, and the other risk factors. There are also many studies evaluating the CAC prevalence in patients with occult metabolic syndrome, ${ }^{33}$ treated with therapeutic irradiation, ${ }^{34}$ dilated cardiomyopathy, ${ }^{35}$ type 2 diabetes mellitus, ${ }^{36}$ obstructive sleep apnea ${ }^{37}$, etc. All these patients had higher CAC prevalence in comparison to normal population. It was due to underlying disorders causing atherosclerosis.

In the present study, of the 38 patients with CAC, $12(4.5 \%)$ were males and 26 (5.4\%) were females. As in our study, in Pornprasertsuk-Damrongsri and Thanakun ${ }^{16}$ and Carter et al's ${ }^{32}$ studies, the CAC prevalence was not different between male and female population. Tamura et $\mathrm{al}^{15}$ and Bayram et $\mathrm{al}^{24}$ revealed that the CAC incidence in female patients was approximately three times higher than the incidence in males. We suggest that all these different CAC prevalences in female and male populations are probably due to the sample of the studies.

Commonly, CACs are formed at the bifurcation point of the vessels where turbulent flow is increased. ${ }^{22}$ In the majority of the reports in normal populations, 15,16,32 the CACs were unilateral and located on the left side rather than the right side.
In the current study, the most of the CACs were unilateral, but generally located on the right side. In another study, Ohbe et $\mathrm{al}^{23}$ investigated the CAC prevalence in the patients older than 80 years. It was found that the most of the CACs were located on the right side as in our study. They showed that CACs on the left side are less detected than those on the right side on PRs. However, we think that these different CAC localizations in the reports may be related to the sample of the studies.

As for diseases and life style factors associated with CACs, hyperlipidemia, hypertension, cardiovascular diseases, smoking, obesity, renal disease, ${ }^{31}$ diabetes mellitus, ${ }^{36}$ obstructive sleep apnea syndrome, ${ }^{37}$ and periodontitis ${ }^{15}$ were reported. In the present study, in 38 patients with CACs, 12 subjects (31.58\%) reported hyperlipidemia, 12 subjects $(31.58 \%)$ reported hypertension, 7 subjects $(18.4 \%)$ reported diabetes mellitus, and 6 subjects $(15.8 \%)$ reported smoking. Pornprasertsuk-Damrongsri et $\mathrm{al}^{16}$ investigated the archival records of 34 CAC patients for the risk factors. It was found that all the patients with CAC were associated with hypertension (52.9\%), diabetes mellitus $(29.4 \%)$, hyperlipidemia (14.7\%), smoking (2.9\%), and other risk factors such as renal disease, cardiovascular disease, etc. ${ }^{16}$ Their findings were consistent with a previous study in terms of hypertension (77.8\%) and diabetes mellitus (22.2\%) reported by Lewis et $\mathrm{al}^{17}$ Carter and colleagues found that obesity $(45.2 \%)$ was most strongly related to the occurrence of CAC. ${ }^{32}$ We think that this relationship may be related to obesity associated co-morbidities including hypertension, hyperlipidemia, diabetes mellitus etc. rather than the disease. Cohen et al ${ }^{14}$ revealed 1879 male patients over age 55 having standard PRs with 71 (3.8\%) showing CACs. In their study, $53.5 \%$ of those patients with CACs had a history of hypertension, $36.6 \%$ had hyperlipidemia, $22.5 \%$ had diabetes mellitus, and $54.9 \%$ were smokers. ${ }^{14}$ Their morbidity rates were higher than the rates of our study as in Tamura et al's ${ }^{15}$ report. These may be due to smaller selected age groups of the both studies in comparison to Cohen et al's $^{14}$ report. However, we think that all these differences in terms of risk factors may be due to ethnicity, dietary factors, lifestyle, and regional differences. 


\section{CONCLUSIONS}

As a result, CACs found as incidental findings on standard PRs may be important markers for future coronary artery disease, strokes and death. ${ }^{14}$ PR should be carefully examined in the area of the carotid artery in not only patients with systemic disease such as diabetes, renal disease etc., but also asymptomatic patients. ${ }^{31}$ The CACs in the present study were detected by standard PR in $5.06 \%$ of the patients with dental problems. Most of the CACs were detected on the right side. The CAC incidence in female patients is approximately two times higher than the rate in male patients in our sample. In the current study, $31.58 \%$ of our patients with CACs had a history of hyperlipidemia, $31.58 \%$ had hypertension, $18.4 \%$ had diabetes mellitus, and $15.8 \%$ had smoking as consistent with the other previous reports. Therefore, any patient with CACs should be evaluated in terms of risk factors for atherosclerosis. According to our knowledge, this study has the highest CACs prevalence in comparison to the other studies. Also, this is the first study done in Cappadocia region and investigating the risk factors related to CAC in the Turkish population. In conclusion, we believe that dentists caring for subjects with dental problems should carefully evaluate their PRs for the evidence of CACs, and refer them for medical evaluation as indicated. So, incidental findings could provide life-saving information.

\section{REFERENCES}

1. Lusis AJ. Atherosclerosis. Nature 2000;407:233-241.

2. Ross R. Atherosclerosis: an inflammatory disease. $N$ Engl $J$ Med 1999;340:115-126.

3. Hertzer NR, O'Hara PJ, Mascha EJ, Krajewski LP, Sullivan TM, Beven EG. Early outcome assessment for 2228 consecutive carotid endarterectomy procedures: the Cleveland clinic experience from 1989 to 1992. J Vasc Surg 1997;26:110.

4. Friedlander $\mathrm{AH}$. Identification of stroke-prone patients by panoramic and cervical spine radiography. Dentomaxillofac Radiol 1995;24:160-164.

5. Hoyert DL, Arias E, Smith BL, Murphy, SL, Kochhanek KD. Deaths: final data for 1999. Natl Vital Stat Rep 2001;49:1113.

6. Williams GR, Jiang JG, Matchar DB, Samsa GP. Incidence and occurrence of total (first-ever and recurrent) stroke. Stroke 1999;30:2523-2528.

7. Matchar DB, Duncan PW. Cost of Stroke. Stroke Clin Updates
1994;5:9-12

8. Olalla MT, Medrano MJ, Sierra MJ, Almazan J. Mortalidad por enfermeddad cerebrovascular en España. Rev Neurol 1999;29:872-878.

9. Prime Ministry Republic of Turkey: Turkish Statistical Institute (Turkstat) Report, 2005, http://www.turkstat.gov.tr (Statistics/social security \& health/health statistics/reason of disease).

10. Almog DM, Tsimidis K, Moss ME, Gottlieb RH, Carter LC. Evaluation of a training program for detection of carotid artery calcifications on panoramic radiographs. Oral Surg Oral Med Oral Pathol Oral Radiol Endod 2000;90:111-117.

11. Anderson CS, Jamrozik KD, Burvill PW, Chakera TM, Johnson GA, Stewart-Wynne EG. Determining the incidence of different subtypes of stroke: results from the Perth Community Stroke Study, 1989-1990. Med J Aust 1993;158:8589

12. Hubar JS. Carotid artery calcification in the black population: a retrospective study on panoramic radiographs. Dentomaxillofac Radiol 1999;28:348-350.

13. Friedlander $A H$, Lande A. Panoramic radiographic identification of carotid arterial plaques. Oral Surg Oral Med Oral Pathol Oral Radiol Endod 1981;52:102-104.

14. Cohen SN, Friedlander AH, Jolly DA, Date L. Carotid calcification on panoramic radiographs: An important marker for vascular risk. Oral Surg Oral Med Oral Pathol Oral Radiol Endod 2002;94:510-514.

15. Tamura $T$, Inui $M$, Nakase $M$, Nakamura $S$, Okumura $K$ Tagawa T. Clinicostatistical study of carotid calcification on panoramic radiographs. Oral Diseases 2005;11:314-317.

16. Pornprasertsuk-Damrongsri S, Thanakun S. Carotid artery calcification detected on panoramic radiographs in a group of Thai population. Oral Surg Oral Med Oral Pathol Oral Radiol Endod 2006;101:110-115.

17. Lewis DA, Brooks SL. Cartoid artery calcification in a general dental population: a retrospective study of panoramic radiographs. Gen Dent 1999;47:98-103.

18. Kumagai M, Yamagishi T, Fukui N, Chiba M. Long-term cigarette smoking increases the prevalence of carotid artery calcification seen on panoramic dental radiographs in male patients. Tohoku J Exp Med 2007;212:21-25.

19. Kumagai M, Yamagishi T, Fukui N, Chiba M. Carotid artery calcification seen on panoramic dental radiographs in the Asian population in Japan. Dentomaxillofac Radiol 2007;36:92-96.

20. Beckstrom BW, Horsley SH, Scheetz JP, et al. Correlation between carotid area calcifications and periodontitis: a retrospective study of digital panoramic radiographic findings in pretreatment cancer patients. Oral Surg Oral Med Oral Pathol Oral Radiol Endod 2007;103:359-366. 
21. Tanaka $T$, Morimoto $Y$, Ansai $T$, et al. Can the presence of carotid artery calcification on panoramic radiographs predict the risk of vascular diseases among 80-yearolds? Oral Surg Oral Med Oral Pathol Oral Radiol Endod 2006;101:777-783.

22. Friedlander AH, Altman L. Carotid artery atheromas in postmenopausal women: their prevalence on panoramic radiographs and their relationship to atherogenic risk factors. J Am Dent Assoc 2001;132:1130-1136.

23. Ohba T, Takata Y, Ansai T, et al: Evaluation of calcified carotid artery atheromas detected by panoramic radiograph among 80-year-olds. Oral Surg Oral Med Oral Pathol Oral Radiol Endod 2003;96:647-650.

24. Bayram B, Uckan S, Acikgoz A, Muderrisoglu H, Aydinalp A. Digital panoramic radiography: a reliable method to diagnose carotid artery atheromas? Dentomaxillofac Radiol 2006;35:266-270.

25. Carter LC. Discrimination between calcified triticeous cartilage and calcified carotid atheroma on panoramic radiography. Oral Surg Oral Med Oral Pathol Oral Radiol Endod 2000;90:108-110.

26. Tegos TJ, Kalodiki E, Nicolaides AN. Stroke: management and rehabilitation. Part III of III. Angiology 2000;51:977984.

27. Friedlander AH, Friedlander IK. Identification of stroke prone patients by panoramic radiography. Aust Dent $J$ 1998;43:51-54.

28. Friedlander RH. Panoramic radiography: the differential diagnosis of carotid artery atheromas. J Spec Care Dent 1995; 15:223-227.

29. Friedlander AH, Friedlander I. Panoramic dental radiography: an aid in detecting individuals prone to stroke. $\mathrm{Br}$ Dent $J$ 1996;181:23-26.

30. Madden RP, Hodges JS, Salmen CW, et al. Utility of panoramic radiographs in detecting cervical calcified carotid atheroma. Oral Surg Oral Med Oral Pathol Oral Radiol Endod 2007;103:543-548.

31. Kansu Ö, Özbek M, Avcu N, Gençtoy G, Kansu H, Turgan C. The prevalence of carotid artery calcification on the panoramic radiographs of patients with renal disease. Dentomaxillofac Radiol 2005;34:16-19.

32. Carter LC, Haller AD, Nadarajah V, Calamel AD, Aguirre A. Use of panoramic radiography among an ambulatory dental population to detect patients at risk of stroke. $\mathrm{J} \mathrm{Am}$ Dent Assoc 1997;128:977-984.

33. Friedlander AH, Golub MS. The significance of carotid artery atheromas on panoramic radiographs in the diagnosis of occult metabolic syndrome. Oral Surg Oral Med Oral Pathol Oral Radiol Endod 2006;101:95-101.

34. Friedlander AH, August M. The role of panoramic radiog- raphy in determining an increased risk of cervical atheromas in patients treated with therapeutic irradiation. Oral Surg Oral Med Oral Pathol Oral Radiol Endod 1998;85:339344.

35. Sung EC, Friedlander AH, Kobashigawa JA. The prevalence of calcified carotid atheromas on the panoramic radiographs of patients with dilated cardiomyopathy. Oral Surg Oral Med Oral Pathol Oral Radiol Endod 2004;97:404407.

36. Friedlander AH, Maeder LA. The prevalence of calcified carotid artery atheromas on the panoramic radiographs of patients with type 2 diabetes mellitus. Oral Surg Oral Med Oral Pathol Oral Radiol Endod 2000;89:420-424.

37. Friedlander AH, Yueh R, Littner MR. The prevalence of calcified carotid artery atheromas in patients with obstructive sleep apnea syndrome. J Oral Maxillofac Surg 1998;56:950-954. 